\title{
The prevalence of premature thelarche in girls and gynecomastia in boys and the associated factors in children in Southern China
}

\author{
Jianwei Zhang ${ }^{1,2,3}$, Jinliang $X u^{2,3}$, Lifang Liu ${ }^{3}$, Xiaohua $X^{3}{ }^{3}$ Xinxian Shu ${ }^{3}$, Zhifeng Yang ${ }^{3}$, Lanqiu LV ${ }^{3}$, Xiding Cai ${ }^{3}$,
} Xianjiang $\mathrm{Jin}^{3}$, Zaiyan $\mathrm{Gu}^{3}$ and Junfen $\mathrm{Fu}^{1,3^{*}}$ (i)

\begin{abstract}
Background: To investigate the prevalence and risk factors of premature thelarche (PT) in girls and gynecomastia (GM) in boys in Southern China.

Methods: We conducted a cross-sectional study of preschool children across 9 cities in Zhejiang province. A total of 6273 children in the age-group of 2-7 years were recruited from January 2014 to March 2015. Relevant information was collected from mothers through face-to-face interviews. Logistic regression models were used to examine the correlates of PT and GM. Odds ratios (ORs) with 95\% confidence intervals (Cls) are reported.

Results: The prevalence of PT among girls was $4.8 \%$ and that of GM among boys was $0.8 \%$. One hundred girls were diagnosed with PT before the age of 2 years; 69 (69.0\%) of these girls experienced spontaneous resolution of PT. Twenty-four boys were diagnosed with GM before the age of 2 years; 10 (41.7\%) of these experienced spontaneous resolution of GM. Children borne of mothers with early onset of menarche and those belonging to high-income families were at a higher risk of premature breast development. Greater consumption of eggs was associated with premature breast development in early childhood.
\end{abstract}

Conclusions: Socioeconomic status of family, early onset of menarche in mother, and consumption of eggs were strongly associated with premature breast development in early childhood.

Keywords: Prevalence, Premature thelarche, Gynecomastia, Risk factors, China

\section{Background}

Premature thelarche (PT) refers to isolated early breast development in girls younger than 8 years of age while gynecomastia (GM) refers to the presence of breast tissues in boys [1]. Surveys conducted across the world have shown an increasing trend in the prevalence of PT and GM among young children. A survey of 802 girls in Istanbul (year 2011) revealed an early breast growth rate of $8.9 \%$ among girls aged 8 years [2]. Similarly, the prevalence of PT among Italian and Danish girls under

\footnotetext{
* Correspondence: fjf68@zju.edu.com

'Department of Endocrinology, Children's Hospital of Zhejiang University, School of Medicine, Zhejiang University, Hangzhou, China

${ }^{3}$ Quality control center of children's growth and development of Zhejiang province, Hangzhou, Zhejiang, China

Full list of author information is available at the end of the article
}

the age of 8 years was 11 and $3 \%$, respectively [3, 4]. In a US national multicenter survey (year 1997) of 17,077 girls aged 3-4 years, 3\% of African-American girls and $1 \%$ of white girls were found to have PT. [5] In a recent US regional study, the PT rate among 318 girls of age 1-4 years was found to be $4.7 \%$ [6]. In a multicenter study of 1510 Chinese infants and toddlers in the age-group of 0-4 years, the prevalence of PT and GM was found to be 2.2 and $1.0 \%$, respectively [7].

Epidemiological evidence suggests that diet, environmental toxicity, and socioeconomic status of the family may be potentially associated with PT and GM in young children. Some studies have found an association of early breast development with consumption of phytoestrogen-containing food $[8,9]$ and endocrine disrupting chemicals $[10,11]$. 
However, there is a lack of definitive evidence of this association. Some have claimed that the increased prevalence of obesity among children is responsible for early onset of puberty $[2,12,13]$. Other studies have investigated the influence of gestational and birth-related factors on pubertal onset; according to a study, prematurity may also be a risk factor for PT. [14]

China is a rapidly developing country with tremendous changes in socioeconomic and environmental milieu, especially in the southern areas. While a recent study found an increase in the incidence of PT and GM among Chinese children, robust studies with relatively large sample size are yet to be conducted. Therefore, in this study, we investigated the prevalence and correlates of $\mathrm{PT}$ and GM among Chinese children in the age-group of $2-7$ years.

\section{Methods}

\section{Participants}

The data presented here were obtained from Zhejiang Investigation of Breast Development and Dietary Factors in Infants and Young children. This observational study included a retrospective survey and physical examination. This study was conducted in preschool children in 9 districts of Zhejiang province in Southeast China (Hangzhou, Ningbo, Shaoxing, Taizhou, Wenzhou, Jiaxing, Huzhou, Jinhua, and Lishui). In each district, children aged 2-7 years were randomly selected from a city and countryside preschool using a random number table from January 2014 to March 2015. A multistage, stratified cluster sampling technique was used to select the study sample. This study was approved by the Institutional Review Board of the Children's Hospital of Zhejiang University and informed consent was obtained from the biological mothers of all children.

\section{Questionnaire survey and physical examination}

An interviewer solicited all relevant information from mothers via a face-to-face interview conducted using a specially designed questionnaire. Data pertaining to the following variables were collected in the interview: birth status (gestational weeks and birth weight); infant feeding status (feeding history during the first 6 months and 7-12 months after birth), history of diagnosis of early breast development by endocrinologist (whether the children were diagnosed with early breast development by an endocrinologist; whether it regressed naturally; duration for which the condition lasted); age of mother at menarche; food exposure; and family income. All children underwent physical examination conducted by trained pediatric endocrinologists; data pertaining to the extent of breast development, height, weight, waist circumference, and hip circumference were also collected. In this study, breast development was staged according to the Tanner criteria. Overweight children underwent breast ultrasound examination to assess the presence of early breast development. Children with early breast development were followed every 3 months until natural regression of the breasts or until age 8 if breast tissue persisted.

\section{Statistical analysis}

Data pertaining to continuous variables are presented as mean \pm standard deviation; categorical variables are presented as frequency (percentage). Data pertaining to height, weight, waist circumference, and hip circumference were converted to the corresponding $\mathrm{z}$ values for age and sex. Logistic regression analyses were used to assess the risk factors of PT and GM and the corresponding odds ratios (ORs) with 95\% confidence intervals (CIs) were calculated. The significance level was set at $P<0.05$. All analyses were performed using the SPSS 20.0 statistical package.

\section{Results}

Prevalence and resolution of PT and GM

A total of 6273 children (3295 boys and 2978 girls) in the age-group of 2-7 years were recruited in this study. The mean age of boys and girls was $4.01 \pm 0.92$ and $4.04 \pm 0.97$ years, respectively. Of these, 170 (143 girls and 27 boys) were found to have early breast development; all 170 children were categorized as $\geq$ Tanner Stage 2 (Table 1). The prevalence of PT among girls and that of GM among boys was 4.8 and $0.8 \%$, respectively $(P<0.001)$. One hundred girls were diagnosed with PT at the age of $<2$ years; of these 69 (69.0\%) girls experienced spontaneous resolution of PT, while 31 experienced persistence of PT. Twenty-four boys were diagnosed with GM at the age of < 2 years; of these, 10 (41.7\%) boys experienced spontaneous resolution of GM. Girls who developed

Table 1 Age, sex, and area of residence of subjects with early breast development

\begin{tabular}{lll}
\hline Group & Frequency (PT and GM) & Percentage (\%) \\
\hline Age (years) & & \\
$0-2$ & 124 & 2.0 \\
$2-4$ & 15 & 0.2 \\
$5-7$ & 31 & 0.5 \\
Sex & & \\
Male (GM) & $27(3295)$ & 0.8 \\
Female (PT) & $143(2978)$ & 4.8 \\
Area of residence & & \\
Urban & $102(3301)$ & 3.1 \\
Suburban & $68(2972)$ & 2.3 \\
\hline
\end{tabular}

PT premature thelarche, GM gynecomastia 
PT before the age of 2 years were more likely to experience spontaneous resolution with passage of time as compared to girls who developed PT at the age of $3-7$ years $\left(x^{2}=7.75, P=0.005\right.$; Fig. 1$)$.

\section{Relationship between early breast development and physical growth}

In the overall study population, the development of PT or GM showed a significant association with height, weight, and waist and/or hip circumference (Table 2). However, no significant association of early breast development with BMI was observed either in girls or boys. The mean BMI of children with and without breast development was $16.10 \pm 1.37 \mathrm{~kg} / \mathrm{m}^{2}$ and $17.70 \pm 89.63 \mathrm{~kg} / \mathrm{m}^{2}$, respectively.

\section{Relationship between early breast development and} family environment factors

There was no significant association of early breast development with maternal gestation, birth type, birth weight, feeding history, frequency of exercise by children, and sleep duration (Table 3). Children borne of mothers who had earlier menarche were more likely to develop PT and GM (age at menarche $<12$ years, OR = 6.3, 95\% CI: 4.4-8.8); the risk of PT and GM was particularly high among children borne of mothers who had menarche by the age of 10 years $(\mathrm{OR}=58.2,95 \% \mathrm{CI}$ : $33.6-100.7)$. Family monthly income $<3000$ yuan or $>$ 15,000 yuan was associated with an increased risk of PT and $\mathrm{GM}(\mathrm{OR}=2.2,95 \% \mathrm{CI}: 0.8-6.2$ and $\mathrm{OR}=2.4,95 \%$ CI: 1.8-3.3, respectively). Mode of feeding in the first year, exercise frequency, sleep time, or history of major disease was not associated with PT or GM.
Relationship of early breast development and dietary exposure

Dietary intake of rice, pasta, meat, dairy products, bean products, snacks, drinks, fruits, and vegetables by children was not significantly associated with early breast development (Table 4). Children who consumed greater amount of eggs showed a significantly greater prevalence of PT and GM (F = 41.57, $P<0.001)$.

The resolution of PT and GM was associated with childhood food choices and resolution rates were significantly higher in children who consumed greater amounts of rice $(P<0.001)$, pasta $(P<0.001)$, red meat $(P<0.001)$, fruits $(P<0.001)$, vegetables $(P<0.001)$, and snacks $(P<0.001)$, and lesser amount of eggs $(P=0.02)$ (Table 5).

\section{Discussion}

The prevalence of the early breast development in children varies in different populations. In a study by Wang et al., the prevalence of PT and GM in children aged $<8$ years was $2.4 \%$ in urban areas and $1.0 \%$ in the suburbs of Shanghai, China [15]. Similarly, the prevalence of PT in girls aged 6-8 years was $16.0 \%$ in Haikou City [16]. In the present study, the prevalence of PT and GM in children aged 2-7 years in Zhejiang province was 4.8 and $0.8 \%$, respectively. Our findings are consistent with those reported from Shanghai but different from those reported from Haikou. The prevalence of PT in the present study is lower than that reported from Turkey (8.9\%) [2] and Italy (11\%) [3], but approximates the rates reported from Denmark (3\%) [4] and the US $(4.7 \%)[5,6]$.

Early breast development in young children is a benign and self-limiting phenomenon that typically regresses

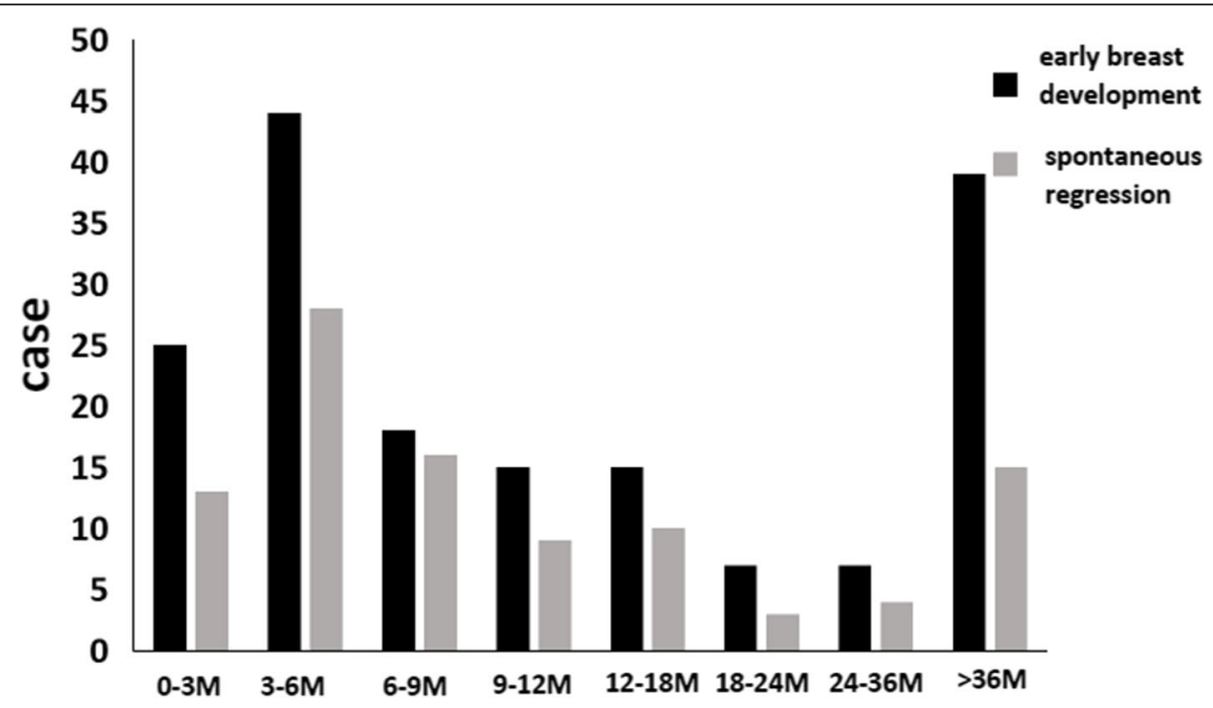

Fig. 1 Age distribution of subjects who experienced spontaneous regression of premature thelarche and gynecomastia 
Table 2 Relationship between early breast development and physical growth status

\begin{tabular}{|c|c|c|c|c|c|}
\hline Growth status & Subjects without PT/GM & Subjects with PT/GM & $\mathrm{F}$ & $t$ & $P$ \\
\hline${ }^{*}$ z Height & $-0.18 \pm 0.98$ & $0.64 \pm 1.41$ & 79.14 & -8.538 & $<0.001$ \\
\hline${ }^{*}$ z Weight & $-0.16 \pm 0.98$ & $0.58 \pm 1.39$ & 67.88 & -7.638 & $<0.001$ \\
\hline${ }^{*} z$ Waist perimeter & $-0.01 \pm 0.99$ & $0.39 \pm 1.30$ & 33.00 & -5.156 & $<0.001$ \\
\hline *z Hip perimeter & $-0.21 \pm 0.98$ & $0.77 \pm 1.44$ & 93.60 & -10.204 & $<0.001$ \\
\hline BMl & $17.70 \pm 89.63$ & $16.10 \pm 1.37$ & 0.12 & 1.385 & 0.177 \\
\hline
\end{tabular}

* $z$ : corrected for sex and age

PT premature thelarche, GM gynecomastia, $B M I$ body mass index

spontaneously with age. The progression of PT to central precocious puberty (CPP) is quite uncommon. Studies have provided very different estimates as to how often progression of PT to CPP occurs with a recent study [17] reporting only $2 \%$ of girls progress while 2 other studies $[18,19]$ reported that $18-20 \%$ progressing from PT to CPP. Persistence of PT or progression of PT to CPP signifies a more complicated condition in early childhood. The reported rates of spontaneous regression of early breast development range from $50.5-69.5 \%$ [20]. In a study of 91 Taiwanese girls with PT, $57.6 \%$ girls experienced spontaneous resolution of PT, while 19\% experienced progression to CPP [21]. In the present study, the resolution rate of PT in girls was $61.5 \%$ (88 of 143) and that of GM in boys was $37.0 \%(10 / 27)$.

We also found that the resolution rate of PT among girls aged $0-2$ years was significantly higher than that among girls aged $>3$ years $(P=0.005)$; this phenomenon may be attributable to the so-called mini-puberty theory. After delivery, the hypothalamo-pituitary-gonadal axis is activated by the low levels of estrogen in newborns, which leads to pubertal levels of estrogen (also referred to as mini-puberty) [22]. In girls, the mini-puberty lasts for about 2-3 years followed by its spontaneous resolution; this explains the higher rates of incidence and resolution of PT in this age-group. The mini-puberty lasts for about 6 months after birth in boys, during which time the long-term testicular functions and sperm production are regulated; this contributes to masculinization of the brain. We postulate that if the mini-puberty is somehow interfered in boys, the gynecomastia would probably occur and persist as found in the current study.

Some studies have reported an association between PT and BMI. In a study by Zeynep et al., the occurrence of PT among Turkish girls with normal BMI was $3.2 \%$ as against $12.3 \%$ among girls with BMI above the 85th percentile [2]. However, others have argued that higher BMI may be a consequence rather than a determinant of PT $[23,24]$. In the current study, the physical growth indices including BMI were not found to be associated with PT or GM; this discrepancy may be attributable to ethnicity-related factors. Zeynep et al. also reported that among girls with normal BMI, only $1.3 \%$ of non-Hispanic white girls had PT whereas the prevalence of PT in non-Hispanic black and Mexican American girls was 12.1 and $19.2 \%$, respectively.

Table 3 Relationship of early breast development with maternal, gestational and economic factors

\begin{tabular}{|c|c|c|c|}
\hline Family factors & Subjects without PT/GM n (\%) & Subjects with PT/GM (\%) & OR $(95 \% \mathrm{Cl})$ \\
\hline \multicolumn{4}{|l|}{ Gestation } \\
\hline Premature birth & $412(97.6)$ & $10(2.4)$ & 1.0 \\
\hline Term birth & $5493(97.3)$ & $153(2.7)$ & $1.2(0.6-2.2)$ \\
\hline Post term birth & $198(96.6)$ & $7(2.7)$ & $1.5(0.6-3.9)$ \\
\hline Birth weight (kg) & $3.38 \pm 0.71$ & $3.35 \pm 0.57$ & $1.0(0.7-1.3)$ \\
\hline \multicolumn{4}{|c|}{ Maternal menarche age (years) } \\
\hline 10 & $29(47.5)$ & $32(52.5)$ & $58.2(33.6-100.7)$ \\
\hline$<12$ & $372(88.4)$ & 49 (11.6) & $6.3(4.4-8.8)$ \\
\hline $12-13$ & $1462(97.3)$ & $40(2.7)$ & $1.4(1.0-2.1)$ \\
\hline$>13$ & $4269(98.1)$ & $81(1.9)$ & 1.0 \\
\hline \multicolumn{4}{|c|}{ Family monthly income (yuan) } \\
\hline $3000-15,000$ & $4555(98.0)$ & $94(2.0)$ & 1.0 \\
\hline$<3000$ & $87(95.6)$ & $4(4.4)$ & $2.2(0.8-6.2)$ \\
\hline$>15,000$ & $1461(95.3)$ & $72(4.7)$ & $2.4(1.8-3.3)$ \\
\hline
\end{tabular}

$P T$ premature thelarche, GM gynecomastia, $O R$ odds ratio, $\mathrm{Cl}$ confidence interval 
Table 4 Relationship between early breast development and food exposure

\begin{tabular}{|c|c|c|c|c|c|}
\hline Food type & Subjects without PT/GM & Subjects with PT/GM & $\mathrm{F}$ & $t$ & $P$ \\
\hline Rice (times/week) & $6.00 \pm 5.81$ & $5.68 \pm 5.81$ & 0.31 & 0.72 & 0.58 \\
\hline Pasta (times/week) & $0.70 \pm 1.92$ & $2.73 \pm 2.11$ & 0.78 & 0.18 & 0.86 \\
\hline Red meat (times/week) & $3.77 \pm 3.66$ & $3.44 \pm 2.91$ & 0.86 & 1.17 & 0.24 \\
\hline White meat (times/week) & $1.98 \pm 2.22$ & $1.71 \pm 1.02$ & 0.48 & 1.63 & 0.15 \\
\hline Sea food (times/week) & $2.36 \pm 1.86$ & $2.27 \pm 2.15$ & 0.35 & 0.62 & 0.55 \\
\hline Eggs (g/week) & $22.35 \pm 7.68$ & $250.86 \pm 31.93$ & 41.57 & 3.21 & $<0.001$ \\
\hline Fresh milk (mL/week) & $420.73 \pm 498.79$ & $408.43 \pm 781.75$ & 1.76 & 0.32 & 0.19 \\
\hline Milk products (mL/week) & $407.78 \pm 406.26$ & $484.04 \pm 307.31$ & 0.52 & 0.52 & 0.47 \\
\hline Fruit juice (mL/week) & $298.26 \pm 552.05$ & $295.71 \pm 202.49$ & 0.19 & 0.6 & 0.66 \\
\hline Carbonated drinks (mL/week) & $188.01 \pm 67.43$ & $183.50 \pm 63.29$ & 2.8 & 0.86 & 0.09 \\
\hline Honey (mL/week) & $194.17 \pm 176.92$ & $186.55 \pm 77.05$ & 0.26 & 0.56 & 0.61 \\
\hline Snacks (times/week) & $3.89 \pm 3.56$ & $3.89 \pm 3.28$ & 0.05 & 0.09 & 0.82 \\
\hline Bean products (times/week) & $3.16 \pm 2.42$ & $2.92 \pm 1.97$ & 0.23 & 1.31 & 0.63 \\
\hline Vegetables (times/week) & $5.17 \pm 5.01$ & $4.93 \pm 4.45$ & 1.81 & 0.6 & 0.18 \\
\hline Fruits (times/week) & $4.28 \pm 4.14$ & $4.21 \pm 3.76$ & 0.45 & 0.21 & 0.5 \\
\hline
\end{tabular}

Data presented as mean \pm standard deviation

PT premature thelarche, GM gynecomastia

Maternal age at menarche may provide some insights into the role of genetic factors on PT and puberty. Some studies have found an association between maternal age at menarche and PT $[17,25]$, while others have found no such association [2, 26]. In the current study, we found a significant association of maternal age at menarche with PT and GM. Children whose mothers experienced menarche at the age of $<12$ years were more likely to develop PT or GM in early childhood.
In the present study, the intake of eggs was associated with both PT and GM. Nutritional factors have been frequently considered as putative agents that could influence early breast development in children. Bratberg et al. reported that children with surplus dietary intake were more likely to develop PT or GM [27]. Gunther et al. found that children aged 5-6 years who regularly consumed animal proteins were at a higher risk of early breast development [28]. However, other studies found

Table 5 Relationship between the resolution of PT/GM and food exposure

\begin{tabular}{|c|c|c|c|c|c|}
\hline Food type & Resolution & No resolution & $\mathrm{F}$ & $t$ & $P$ \\
\hline Rice (times/week) & $7.85 \pm 6.39$ & $2.72 \pm 3.07$ & 127.7 & 6.29 & $<0.001$ \\
\hline Pasta (times/week) & $3.17 \pm 2.47$ & $2.14 \pm 1.30$ & 11.27 & 3.24 & $<0.001$ \\
\hline Red meat (times/week) & $3.94 \pm 3.40$ & $2.68 \pm 1.90$ & 20.91 & 2.84 & $<0.001$ \\
\hline White meat (times/week) & $1.63 \pm 1.16$ & $1.64 \pm 0.74$ & 3.14 & 0.66 & 0.07 \\
\hline Sea food (times/week) & $2.52 \pm 2.63$ & $1.89 \pm 1.14$ & 4.11 & 1.89 & 0.44 \\
\hline Eggs (g/week) & $23.09 \pm 71.34$ & $626.92 \pm 4902.61$ & 5.25 & 1.22 & 0.02 \\
\hline Fresh milk (mL/week) & $424.77 \pm 342.94$ & $358.60 \pm 159.32$ & 2.37 & 1.52 & 0.13 \\
\hline Milk products (mL/week) & $559.74 \pm 387.16$ & $446.10 \pm 328.28$ & 0.67 & 2.01 & 0.42 \\
\hline Fruit juice (mL/week) & $296.45 \pm 223.66$ & $287.12 \pm 170.84$ & 0.11 & 0.3 & 0.74 \\
\hline Carbonated drinks (mL/week) & $173.78 \pm 66.30$ & $163.09 \pm 57.56$ & 0.38 & 1.09 & 0.54 \\
\hline Honey (mL/week) & $154.92 \pm 77.99$ & $151.08 \pm 72.27$ & 0.01 & 0.33 & 0.93 \\
\hline Snacks (times/week) & $4.56 \pm 3.51$ & $2.98 \pm 2.69$ & 13.8 & 3.2 & $<0.001$ \\
\hline Bean products (times/week) & $3.06 \pm 2.23$ & $2.60 \pm 1.49$ & 6.24 & 1.54 & 0.13 \\
\hline Vegetables (times/week) & $6.02 \pm 5.17$ & $3.35 \pm 2.55$ & 24.71 & 4.04 & $<0.001$ \\
\hline Fruits (times/week) & $5.18 \pm 4.33$ & $2.87 \pm 2.23$ & 20.26 & 4.14 & $<0.001$ \\
\hline
\end{tabular}


no significant association of intake of milk and eggs with early breast development [2] or between consumption of soya bean derived products and PT [20,29].

Environmental endocrine disrupting chemicals and oestrogen-like agents have often been suggested as underlying causes of early breast development in young children [30-32]. These agents most likely influence the children through contamination of food. There is widespread concern about the illegal usage of endocrine disrupting chemicals in poultry, dairy, and fish farms. Given the poor regulation of Chinese poultry farms, these harmful agents may pollute the eggs and exposure of children to such eggs may increase the prevalence of PT and GM.

In the current study, we found a significant association of PT and GM with family income. Children belonging to families whose monthly income was either $<3000$ yuan or $>15,000$ yuan had a higher risk of PT and GM as compared to their counterparts with a family income of 3000-15,000 yuan. These results may suggest that early breast development in children from poor families may be linked to greater exposure to environmental pollutants while in children from rich families, the association may be attributable to surplus nutrition and/or greater intake of endocrine disrupting chemicals and oestrogen-like agents through animal proteins.

Some limitations of our study need to be considered. First, although the study was conducted by trained endocrinologists, the inter-observer variability with respect to examination findings cannot be ruled out. Second, distinction between girls with PT and those with Gonadotropin-releasing hormone $(\mathrm{GnRH})$-dependent precocious puberty may be challenging especially among younger girls [33, 34]; long term follow-up is required to distinguish between these concitions.

In summary, we found that dietary factors may influence early breast development in young children. Environmental contamination of food with endocrine disrupting chemicals and oestrogen-like agents may affect the children. Premature thelarche among girls aged $<2$ years was more likely to be resolved than those developed PT at a later age. While once the gynecomastia occurred in boys, it was more likely to remain. The discrepancy in the reported correlates of early breast development in children suggests the need for further investigations to provide more definitive evidence.

\section{Conclusions}

This study examined the prevalence of premature thelarche among girls and that of gynecomastia among boys in Southern China. The prevalence rates approximated those reported from some other countries. The socioeconomic status of family, early onset of menarche in mother, and consumption of eggs were strongly associated with premature breast development in early childhood. Greater attention should be paid to the diet of children and adolescents to prevent breast development.

\section{Abbreviations}

Cls: Confidence intervals; GM: Gynecomastia; ORs: Odds ratios; PT: Premature thelarche

\section{Acknowledgements \\ The authors would like to thank all pediatric patients, their parents as well as the colleagues at the Quality control center of children's growth and development of Zhejiang province. \\ Funding \\ This work was supported by medical and health science and technology project of Zhe jiang Province (2017KY668); the Research Council of the Science Technology Department of Zhejiang Province (2016C33130) and the National Key Research and Development Programe of China (No. 2016YFC1305301). The funders were not involved in the study design, data collection, analysis, interpretation, or manuscript preparation.}

\section{Availability of data and materials}

The datasets used and/or analyzed in the current study are available from the corresponding author on reasonable request.

\section{Authors' contributions}

JZ contributed to the conception and design of the study, data analysis, and preparation of the manuscript. JX, LFL, XX, XS, ZY, LL, XC, XJ, ZG, are contributed to data collection, study conduct, and drafting of the manuscript. JF contributed to the conception and design of the study and data analysis. All authors have read and approved the final manuscript.

\section{Ethics approval and consent to participate}

Written informed consent was obtained from the parents of all patients. A copy of the written consent is available for review by the editor of this journal. Written informed consent was obtained from the parents of all patients, which were also approved by the ethics committee of our hospital.

Consent for publication

Not applicable.

Competing interests

The authors declare that they have no competing interests.

\section{Publisher's Note}

Springer Nature remains neutral with regard to jurisdictional claims in published maps and institutional affiliations.

\section{Author details}

'Department of Endocrinology, Children's Hospital of Zhejiang University, School of Medicine, Zhejiang University, Hangzhou, China. ${ }^{2}$ Shaoxing women and children hospital, Shaoxing, Zhejiang, China. ${ }^{3}$ Quality control center of children's growth and development of Zhejiang province, Hangzhou, Zhejiang, China.

Received: 1 February 2018 Accepted: 5 February 2019

Published online: 11 April 2019

References

1. Diamantopoulos S, Bao Y. Gynecomastia and premature thelarche: a quide for practitioners. Pediatr Rev. 2007;28(9):e57-68.

2. Atay Z, Turan S, Guran T, Furman A, Bereket A. The prevalence and risk factors of premature thelarche and pubarche in 4- to 8-year-old girls. Acta Paediatr. 2012;101(2):e71-5.

3. Danubio ME, De Simone M, Vecchi F, Amicone E, Altobelli E, Gruppioni G. Age at menarche and age of onset of pubertal characteristics in 6-14-yearold girls from the province of L'Aquila (Abruzzo, Italy). Am J Hum Biol. 2004;16(4):470-8. 
4. Aksglaede L, Sørensen K, Petersen JH, Skakkebaek NE, Juul A. Recent decline in age at breast development: the Copenhagen puberty study. Pediatrics. 2009;123(5):e932-9.

5. Herman-Giddens ME, Slora EJ, Wasserman RC, et al. Secondary sexual characteristics and menses in young girls seen in office practice: a study from the pediatric research in office settings network. Pediatrics. 1997;99(4):505-12.

6. Curfman AL, Reljanovic SM, McNelis KM, et al. Premature thelarche in infants and toddlers: prevalence, natural history and environmental determinants. J Pediatr Adolesc Gynecol. 2011;24(6):338-41.

7. Wang $Y$, Wang A, Kong $L$, et al. Multi-center study of premature thelarche and gynecomastia in Chinese infants and toddlers. Zhonghua Er Ke Za Zhi. 2014;52(1):5-10.

8. Andersson AM, Skakkebaek NE. Exposure to exogenous estrogens in food: possible impact on human development and health. Eur J Endocrinol. 1999;140(6):477-85.

9. Daxenberger A, Ibarreta D, Meyer HH. Possible health impact of animal oestrogens in food. Hum Reprod Update. 2001;(7(3):340-55.

10. Landrigan P, Garg A, Droller DB. Assessing the effects of endocrine disruptors in the National Children's study. Environ Health Perspect. 2003;111(13):1678-82.

11. Kaplowitz PB, Slora EJ, Wasserman RC, Pedlow SE, Herman-Giddens ME. Earlier onset of puberty in girls: relation to increased body mass index and race. Pediatrics. 2001;108(2):347-53.

12. Nelson KG. Premature thelarche in children born prematurely. J Pediatr. 1983;103(5):756-8

13. Varimo $T$, Huttunen $H$, Miettinen PJ, et al. Precocious puberty or premature Thelarche: analysis of a large patient series in a single tertiary center with special emphasis on 6- to 8-year-old girls. Front Endocrinol (Lausanne). 2017:8:213.

14. Marshall WA, Tanner JM. Growth and physiological development during adolescence. Annu Rev Med. 1968;19:283-300.

15. WANG Defen, WANG Wei, HE Qingbo: A survey of the breast development among 2-13 years old girls in Shanghai area.Chin J Endoerinol Metab 2002, 18(4):297-299.

16. Yi R, Zhituan T, Guixiang $L$. The investigation of Premature thelarche among 6-8 years old girls in haikou. Guangdong Med J. 2014;35(2):272-3.

17. Bizzarri C, Spadoni GL, Bottaro G, et al. The response to gonadotropin releasing hormone $(\mathrm{GnRH})$ stimulation test does not predict the progression to true precocious puberty in girls with onset of premature thelarche in the first three years of life. J Clin Endocrinol Metab. 2014;99(2):433-9.

18. Zhu SY, Du ML, Huang TT. An analysis of predictive factors for the conversion from premature thelarche into complete central precocious puberty. J Pediatr Endocrinol Metab. 2008;21(6):533-8.

19. Pasquino AM, Pucarelli I, Passeri F, Segni M, Mancini MA, Municchi G. Progression of premature thelarche to central precocious puberty. J Pediatr. 1995;126(1):11-4.

20. de Vries L, Guz-Mark A, Lazar L, Reches A, Phillip M. Premature thelarche: age at presentation affects clinical course but not clinical characteristics or risk to progress to precocious puberty. J Pediatr. 2010;156(3):466-71.

21. Lee CT, Tung YC, Tsai WY. Premature thelarche in Taiwanese girls. J Pediatr Endocrinol Metab. 2010;23(9):879-84.

22. Kurtoğlu S, Baştuğ O. Mini puberty and its interpretation. Turk Pediatri Ars. 2014:49(3):186-91.

23. Demerath EW, Li J, Sun SS, et al. Fifty-year trends in serial body mass index during adolescence in girls: the Fels longitudinal study. Am J Clin Nutr. 2004:80(2):441-6.

24. García CB, Gónzalez VA, Frías GE, Arana CC, Díaz ME, Tolmo MD. Assessment of the secular trend in puberty in boys and girls. An Pediatr (Barc). 2010; 73(6):320-6

25. Bing FENG, Gui-mei LI, Jing-shi QU. MA Li-xia1: Relationship between breast development age of idiopathic central precocious puberty girl and maternal age at menarche and maternal height. CJCHC APR. 2011;19(4):348-50.

26. Hongjuan L, Ye JC. Genetic and Environmental Influence on the Sexual Characteristics of Pubertal Girls. Chin J Sch Health. 2006;10(27):834-5.

27. Bratberg GH, Nilsen TI, Holmen TL, Vatten LJ. Early sexual maturation, central adiposity and subsequent overweight in late adolescence. A four-year follow-up of 1605 adolescent Norwegian boys and girls: the young HUNT study. BMC Public Health. 2007;7:54.
28. Günther AL, Karaolis-Danckert N, Kroke A, Remer T, Buyken AE. Dietary protein intake throughout childhood is associated with the timing of puberty. J Nutr. 2010;140(3):565-71.

29. Giampietro PG, Bruno G, Furcolo G, et al. Soy protein formulas in children: no hormonal effects in long-term feeding. J Pediatr Endocrinol Metab. 2004;17(2):191-6.

30. Jurewicz J, Hanke W. Exposure to phthalates: reproductive outcome and children health. A review of epidemiological studies. Int J Occup Med Environ Health. 2011;24(2):115-41.

31. Massart F, Saggese G. Oestrogenic mycotoxin exposures and precocious pubertal development. Int J Androl. 2010;33(2):369-76.

32. Weng YI, Hsu PY, Liyanarachchi S, et al. Epigenetic influences of low-dose bisphenol a in primary human breast epithelial cells. Toxicol Appl Pharmacol. 2010;248(2):111-21.

33. Freire AV, Escobar ME, Gryngarten MG, et al. High diagnostic accuracy of subcutaneous Triptorelin test compared with GnRH test for diagnosing central precocious puberty in girls. Clin Endocrinol. 2013;78(3):398-404.

34. Mogensen SS, Aksglaede L, Mouritsen A, et al. Diagnostic work-up of 449 consecutive girls who were referred to be evaluated for precocious puberty. J Clin Endocrinol Metab. 2011;96(5):1393-401.
Ready to submit your research? Choose BMC and benefit from:

- fast, convenient online submission

- thorough peer review by experienced researchers in your field

- rapid publication on acceptance

- support for research data, including large and complex data types

- gold Open Access which fosters wider collaboration and increased citations

- maximum visibility for your research: over $100 \mathrm{M}$ website views per year

At BMC, research is always in progress.

Learn more biomedcentral.com/submissions 